\title{
DOES COMPUTER USE PROMOTE THE MATHEMATICAL PROFICIENCY OF ELL STUDENTS?
}

\author{
SUNHA KIM \\ MIDO CHANG \\ Virginia Polytechnic Institute and State University
}

\begin{abstract}
The study explored the effects of computer use on the mathematical performance of students with special attention to ELL students. To achieve a high generalizability of findings, the study used a U.S. nationally representative database, the Early Childhood Longitudinal Survey Kindergarten Cohort (ECLS-K), and adopted proper weights. The study conducted both crosssectional and longitudinal analyses to examine the direct and longitudinal effects of three types of computer use: home computer access, computer use for various purposes, and computer use for math. The study found positive effects of home computer access and computer use for various purposes for English-speaking groups. It is important to note that computer use for math was associated with a reduced gap in math achievement between native English-speaking and ELL students. In particular, when Hispanic and Asian students frequently used computers for math, they showed high math performances when compared with their English-speaking counterparts.
\end{abstract}

\section{INTRODUCTION}

In a famous book on mathematics education, Adding it $U p$, one of the authors wrote in the preface, "There has never been a time when U.S. students excelled in mathematics" (Kilpatrick, Swafford, \& Findell, 2001, p. xiii). As indicated

(C) 2010, Baywood Publishing Co., Inc. doi: 10.2190/EC.42.3.c

http://baywood.com 
here, the low mathematical achievement of U.S. students has placed a great burden upon educators. According to a report from the Organization for Economic Cooperation and Development (OECD) in 2003, students in 23 countries showed higher achievement than U.S. students among the 29 OECD countries that participated in the international assessments on mathematics. This relative position had not changed as of 2006 (Provasnik, Gonzales \& Miller, 2009).

Adding to the problem in American education, many minority students, including English Language Learners (ELL), constantly show much lower mathematical performance than the average performance level of American students. A study done by Lee, Grigg, and Dion (2007) analyzed data from 197,700 fourth graders and 153,000 eighth graders from the National Assessment of Educational Progress (NAEP) and showed an apparent performance gap in mathematics between ELL and native-born English-speaking students. The study also showed that the disparity, which was already large in fourth grade (217 for ELL vs. 242 for English-speaking), became wider at the eighth grade (245 for ELL vs. 282 for English-speaking). Similarly, Albus, Thurlow, and Liu (2002) reported low math performances of ELL students in K-12 schools in four states: Maine, Massachusetts, North Carolina, and Wisconsin.

It is imperative to find ways to promote the mathematical competence of ELL students, as their numbers are ever increasing. During the 10 -year period from 1995 to 2005, the growth rate of ELL students was $57.17 \%$ in PK-12, compared to $3.66 \%$ of the growth in total enrollment (NCELA, 2009). Summarizing this pattern, U.S. public schools reported an enrollment of approximately 5,000,000 ELL students during the 2005-2006 school year (Pearson, 2009). Despite the increased number of ELL students and the great need to accommodate these students, not enough research has been done to suggest instructional methods that would help ELL students to succeed in school (Clarkson, 2008).

In response, this research has attempted to explore computer use as an important educational resource to improve mathematical achievement with special attention to those effects for ELL students. Educators expect that the advanced features of computers will mediate difficulties that ELL students may experience. Computers can provide vocabulary and comprehension support for ELL students, who have difficulty in understanding instructions during the classes (Proctor, Dalton, \& Grisham, 2007). ELL students can also learn at their own pace by utilizing the asynchronous features of computer-based learning (Gerbic, 2006).

To examine the effects of computers, the study utilized a U.S. nationally representative database, Early Childhood Longitudinal Survey Kindergarten Cohort (ECLS-K). To have a high generalizability and to reach valid research conclusions, the study adopted proper weights and treated design effects. As a main analysis, the study conducted both cross-sectional and longitudinal analyses 
to examine the direct and longitudinal effects of computer use on students' math performance. The following research questions have guided the study.

1. What are the cross-sectional (direct) and longitudinal effects of the three computer variables?

a. home computer access

b. computer use for various purposes

c. computer use for math

2. Do the effects of three computer variables vary by native English-speaking and ELL status?

\section{LITERATURE REVIEW}

\section{Mathematical Performance and ELL Students}

The NAEP 2007 reports that ELL students show low mathematical performance. According to Lee, Grigg, and Dion (2007), 44\% of ELL students scored "below basic" when compared with $16 \%$ of non-ELL students in fourth grade. The gap became wider in eighth grade. About $70 \%$ of ELL students scored "below basic" while $27 \%$ of non-ELL students scored "below basic" (Lee, Grigg, \& Dion, 2007). Similarly, Albus, Thurlow, and Liu (2002) reported low math achievement scores of ELL students in elementary, middle, and high schools based on four states' math assessments (Maine, Massachusetts, North Carolina, and Wisconsin). Using the ECLS-K, Reardon and Galindo (2007) also examined the mathematical performance of Hispanic elementary students and found that Hispanic students who use English as their primary language had higher mathematical performance than Hispanic students from non-English speaking homes. Abedi's study (2002) also shared the above findings regarding the low performance of ELL students using data from four districts in the United States and compared the mathematical performance of ELL and English-speaking students. By separating out each component of mathematical performance, the author showed that ELL students' skills were much lower than those of Englishspeaking students in math analytical skills, concepts, estimation, and problem solving. However, their skills in procedural fluency, especially mathematical computations that do not require English language skills, were not as low as in the other components.

\section{Math Performance and Computers}

While educators have used computers to assist students to learn math, there has been no consensus on the effects of the overall use of computers on students' achievement. Many studies dealing with a wide range and scope of computer use 
have reported mixed results. This study narrowly identified specific computer uses that can benefit students' mathematical achievement. For this goal, the study analyzed the effects of three levels of computer use - computer access at home, computer use at school for math, and computer use for various purposes - on the mathematical performance of students, paying special attention to ELL students. The discussion regarding the three computer variables will be presented in this order throughout the study.

Studies on home computer use for U.S. students have indicated the overall positive effects. Du, Havard, Yu, and Adams (2004) reported the positive effects of home computers and the frequency of computer use at home on composite achievement scores of reading and math by studying tenth graders from the Educational Longitudinal Study (ELS) 2002 database. Papanastasiou and Ferdig (2006) found a similar positive effect of computer use at home on math achievement using the U.S. data from the Program for International Student Assessment (PISA). However, the effects of home computers were found to be different in a study based on international students from the results of U.S. data. Fuchs and Wößmann (2005), using the international student data of PISA 2000, showed that the mere availability of computers at home had a negative effect on the mathematical achievement of students, although home computer use for specific purposes (e.g., e-mail and Web pages) indicated a positive effect.

Along with home computer use, researchers have explored the effects of computer use for various purposes. Mostly, studies showed a positive association between mathematical achievement and computer use for various purposes. For example, the frequency of using computers for word processors and electronic communications, for educational software, and for school work was significantly associated with high mathematics performance of students (Du et al., 2004; Fuchs \& Wößmann, 2005; Papanastasiou \& Ferdig, 2006). However, when students were asked to use computers for tasks that required too high a level of proficiency, they were negatively influenced by computer use. Papanastasiou and Ferdig (2006) in particular showed that a higher frequency of using computers for programming, spreadsheets, and drawing was associated with a low school performance.

Although studies on computer use in school have shown mixed results (Du et al., 2004; Fuchs \& Wößmann, 2005), research results on students' computer use for math have indicated consistently positive effects on math performance. By analyzing the computer use of 130 students from middle schools, Lei and Zhao (2007) found a higher frequency of computer use for math to have a positive impact on students' math GPA. Mendicino, Razzaq and Heffernan (2009) explored the effects of web-based conditioning for mathematical homework in which fifth grade students could get immediate feedback and help from the web. The authors found significantly better math achievement from students doing web-based homework compared with those doing traditional paper-and-pencil homework. 


\section{ELL Students and Computers}

Educators have paid some attention to computers as a way to improve the academic achievement of ELL students. Considering that ELL students spend more time on computers at home than native English-speaking students do (Parmar, Harkness, \& Super, 2008), the study on the effects of computer use for ELL students is particularly important. Parmar, Harkness, and Super (2008) examined the parental involvement in daily educational activities of their children aged 3 to 6 years. The authors found that Asian immigrant parents used computers more than Euro-American parents when they played with their children.

Studies have shown that various features of computers have effectively assisted learning for ELL students in school. For example, Proctor, Dalton, and Grisham (2007) utilized computers to improve the reading achievement of fourth grade Hispanic ELL students. The authors embedded features of technology to provide vocabulary and comprehension supports, including text-to-speech read-aloud functionality. The study results showed that the frequency of computer use was associated with the reading achievement of ELL students.

Similar effects were noted when Meskill (2005) analyzed how one veteran elementary teacher employed computers to help ELL students in learning academic language and social skills. To enrich her instruction, the teacher used computer games and simulations. Making instruction easier by using advanced features of computers, the teacher was able to draw and maintain attention, increase motivation, and encourage problem-solving in ELL students.

Computer use benefited not only ELL children, but also adult immigrant learners. One study examined the effects of computer-based instruction for Hispanic immigrant adult learners. Computer-based instruction has the option of delivering content via pictures, movies, or texts in Spanish (Anger, Tamulinas, Uribe, \& Ayala, 2004).

Further research has underscored the importance of specific features of computers to support ELL students. Studies in which computers were used, but without specific features for ELL students, indicated no benefits of computer use for ELL students. Prinsen, Volman, and Terwel (2007) studied computersupported learning environments for 120 students from an elementary school. The authors found that students with immigrant parents participated less in virtual discussions due to their limited English skills than did their peers who had non-immigrant parents. Segers, Takke, and Verhoeven (2004) examined the vocabulary learning of immigrant and native kindergartners when stories were read by teachers or by computers. The authors found that immigrant children acquired significantly more vocabulary when teachers read the stories than when computers did. The authors speculated that the teachers were more adaptive in reading children's facial expressions, elaborating stories with extra words, and providing more gestures and non-verbal expressions. Thus, the authors suggested 
including animation features in computer programs to supply extra support for ELL students.

\section{METHOD}

\section{Data Sources}

The study used a nationwide longitudinal dataset, the Early Childhood Longitudinal Survey Kindergarten Cohort (ECLS-K), from kindergarten through fifth grade. The sampling method of the ECLS-K used a multistage probability sample design. In the primary sampling of the ECLS-K, the units were randomly selected from 90 strata of geographic areas consisting of counties. In the second stage, schools were randomly selected within sampled counties. A total of 1,277 schools, 914 public and 363 private, participated in the data collection. At the final stage, all students within the selected schools were selected to be samples (Tourangeau, Nord, Le, Pollack, Atkins-Burnett, \& Hausken, 2006). The study accounted for these non-random data selection methods of the ECLS-K by applying proper weights and treating design effects. In this way, we were able to reach research findings that can be representative of the national population. Among the six total available data waves, the study used four waves of spring 1998 kindergarten, spring 1999 first grade, spring 2001 third grade, and spring 2003 fifth grade.

\section{Variables}

The main predictor variables for the study were three computer variables: a) computer access at home; b) computer use for variety of purposes; and c) computer use to learn math. Computer access at home was measured by a survey item, "Do you have a home computer your child uses?" The responses for home computer access were coded 0 for no and 1 for yes. The item measuring the proficiency levels of computer use for variety of purposes asked "Does this child use the computer for a variety of purposes?" and the responses were measured on a 5-point scale ranging from 1 (Not yet) to 5 (Proficient). The frequencies of computer use to learn math were measured by a question, "How often do children in your classes use computers to learn math?" The responses for computer use to learn math were equated to have them at the same scale because those responses were differently measured at different waves. For first two waves, the frequencies were ranged from 1 (Never) to 6 (Daily) while for last two waves ranged from 1 (Never) to 4 (Almost every day).

Item response theory scale scores in mathematics (Math-IRT) were used as the major dependent variable for this study. Math-IRT in the ECLS-K database represents estimates of the number of items students would have answered correctly if they had taken all questions (Tourangeau et al., 2006). Math-IRT is expected to show the major advantages in dealing with longitudinal growth 
modeling because item response theory scale scores ensure that the scores at different time points are measured on a comparable scale (Hox, 2002). Therefore, Math-IRT allowed us to specify the math achievement scores of all four waves without applying an equating process.

As the objectives of the study indicate, this study focused on immigrant students who speak a language other than English as their primary language. Two language groups were created from kindergarten to fifth grade: English-only (English), and English-Language-Learner (ELL). In the study, ELL students were defined as immigrant students who speak a language other than English as a primary language. They were selected by combining information regarding multiple variables: home language of the child, primary language at home, and frequency of speaking non-English at home. Based on information of language status, one dummy variable of ELL was created: 1 indicated students who spoke non-English at home and demonstrated difficulties in English; 0 was coded for English speaking students. The important contextual variable for student academic performance, socioeconomic status (SES), was used as a covariate to control for its effect in this study. We used the SES scale score, which is a composite score of parents' income, educational levels, and occupations. This study also used the age variable of the student's age in months when the assessment occurred. Additionally, the study included the gender as another contextual variable.

Taking advantage of the large samples available on the ECLS-K database, the total database was split into four separate ethnic groups in accordance with the methods used in prior studies of ethnic differences. The main purpose of the separate analyses was to examine the differential effects of computer variables on language minority students within each ethnic group (i.e., Caucasian, Black, Hispanic, and Asian). Another statistical benefit of applying separate analyses was the alleviation of collinearity, because the variables for the ethnic groups became a constant, thereby reducing the number of predictor variables within the model. More importantly, interpretation became straightforward because it did not depend on an indirect interpretation that compared the results for each ethnic group with those of another ethnic group (i.e., the reference group).

\section{Cross-Sectional Analyses}

The study used the AM statistical software and applied Taylor Series sampling units for each grade to treat the design effects in the cross-sectional analyses (American Institutes for Research, 2006). The design effects often become problematic when the students are selected from the same group (cluster), as was the case in the ECLS-K; they tend to share the common aspects of the group and, thus, can show a high correlation among their outcomes. The shared characteristics often bring forth lower error variability than warranted. The study also applied four separate weights (C2CW0, C4CW0, C5CW0, and C6CW0) of child-level assessment scores with 90 replicate weights which were the strata of 
the multistage random sampling of the ECLS-K. By applying the weights and replicate weights, the study designed the sample to have full representation of student populations at each grade. After treating weights and design effects, a multiple cross-sectional regression analysis using AM Statistical Software was conducted.

The cross-sectional analyses of four grades were separately specified with the variables of student age (Age), one dummy language group (ELL), three computer variables (HomeCom, ComPurpose, and ComMath), and three interaction terms of three computer variables with one language group (ELLHomeCom, ELLComPurpose, and ELLComMath), and social class (SES) and gender (Gender) as,

$$
\begin{aligned}
& Y_{i}=\beta_{0}+\beta_{1}(\text { Age })+\beta_{2}(\text { ELL })+\beta_{3}(\text { HomeCom })+\beta_{4}(\text { ComPurpose })+ \\
& \beta_{5}(\text { ComMath })+\beta_{6}(\text { ELLHomeCom })+\beta_{7}(\text { ELLComPurpose })+ \\
& \beta_{8}(\text { ELLComMath })+\beta_{9}(\text { SES })+\beta_{10}(\text { Gender })+\mathrm{e}
\end{aligned}
$$

where $Y_{i}$ indicates a dependent variable; $\beta_{0}$ is the intercept; $\beta_{1}$ indicates the effect of Age on math scores; $\beta_{2}$ indicates the effect of the ELL on math scores; $\beta_{3}$ indicates the effect of home computer access on math scores; $\beta_{4}$ indicates the effect of ComPurpose; $\beta_{5}$ indicates the effect of ComMath; $\beta_{6}$ indicates the interaction effect of HomeCom and the ELL group on math scores; $\beta_{7}$ indicates the interaction effect of ComPurpose with the ELL group; $\beta_{8}$ indicates the interaction effect of ComMath with the ELL group; $\beta_{9}$ indicates the effect of SES; and $\beta_{10}$ indicates the effect of Gender.

\section{Longitudinal Analysis}

As another main statistical tool, this study adopted a two-level longitudinal hierarchical linear modeling (HLM). The HLM analyzed the longitudinal effects of computer variables on the mathematical achievement of students after controlling for the effects of the other covariates (language status, SES, gender, and age) using four waves of data. HLM is a statistical methodology for examining hierarchical or nested data. The study used a longitudinal panel weight $\left(\mathrm{C} 2 \_6 \mathrm{FC} 0\right)$ encompassing the four waves of assessment data as well as representing the full national student population at each wave. Especially, the weight $\mathrm{C} 2$ 6 $6 \mathrm{FC} 0$ contains the highest non-zero values (98\%) among all available longitudinal weights from kindergarten to fifth grade (Tourangeau et al., 2006). Therefore, we were able to perform analyses based on the largest samples using the ECLS-K.

In the longitudinal analysis, the model was built to examine the effects at the student level by specifying computer uses as time-varying covariates at Level 1 (Growth Level). This specification method allowed us to look at the effects of 
three computer variables on achievement at each wave. The Level 1 model also includes Age and SES as time-varying covariates as follows:

$$
\begin{aligned}
& Y_{i}=\pi_{0}+\pi_{1} *\left(A G E_{-} N\right)+\pi_{2} *(\text { SES })+\pi_{3} *(\text { HomeCom })+\pi_{4} *(\text { ComPurpose })+ \\
& \pi_{5} *(\text { ComMath })+e
\end{aligned}
$$

where $Y_{i}$ is a dependent variable; $\pi_{0}$ is the initial value of the dependent variable (a math score at spring semester of kindergarten); $\pi_{1}$ is a linear growth parameter, indicating the growth rate of math scores associated with the student age; $\pi_{2}$ is a linear growth parameter indicating the growth rate of math scores associated with SES; $\pi_{3}$ is a linear growth parameter indicating the growth rate of math scores associated with Home Computer Access; $\pi_{4}$ is a linear growth parameter indicating the growth rate of math scores associated with computer use for various purposes; and $\pi_{5}$ is a linear growth parameter indicating the growth rate of math scores associated with computer use for Math.

Level 2 was designed to show the interaction effects of student language status with the growth of math performance and the computer variables. With an initial model (unconditional model), we found the random components of computer variables and age are not significant. Thus, the variables of Age, HomeCom, ComPurpose, and ComMath were specified as fixed by having the values of $r_{1}, r_{3}, r_{4}$, and $r_{5}$ zero in the model. The effects of intercept and SES were specified as random by specifying $r_{0}$ and $r_{2}$ in the model. The final Level 2 model was specified as:

$$
\begin{aligned}
& \pi_{0}=\beta_{00}+\beta_{01} *(E L L)+\beta_{02} *(\text { Gender })+r_{0} \\
& \pi_{1}=\beta_{10}+\beta_{11} *(E L L) \\
& \pi_{2}=\beta_{20}+r_{2} \\
& \pi_{3}=\beta_{30}+\beta_{31} *(E L L) \\
& \pi_{4}=\beta_{40}+\beta_{41} *(E L L) \text { and } \\
& \pi_{5}=\beta_{50}+\beta_{51} *(E L L)
\end{aligned}
$$

The coefficient, $\beta_{00}$, is the intercept, indicating the grand mean of math scores; $\beta_{01}$ is the effect of the ELL-group on math scores; $\beta_{02}$ is the effect of gender on math scores; $\beta_{10}$ is the effect of age on math; $\beta_{11}$ is the interaction effect of age with ELL group on math scores; $\beta_{20}$ is the effect of SES on math scores; $\beta_{30}$ is the effect of computer access at home on math scores; $\beta_{31}$ is the interaction effect of computer access at home with the ELL group; $\beta_{40}$ is the effect of computer use for various purposes on math scores; $\beta_{41}$ is the interaction effect of computer use for various purposes with the ELL group; $\beta_{50}$ is the effect of computer use to learn math on math scores; $\beta_{51}$ is the interaction effect of computer use to learn math with the ELL group; $\mathrm{r}_{0}$ is random effect of math scores; and $\mathrm{r}_{2}$ is the random effect of the growth of SES. 


\section{RESULTS}

\section{Comparison of Math Achievement Scores of Two Linguistic Groups}

In the first analysis, as presented in Figure 1, the study explored the growth patterns of math performance and the performance gap between two language groups, English-speaking and ELL groups. The study adopted Math-IRT scores as the dependent variable due to well-known advantages of IRT scales scores in longitudinal analysis (Hox, 2002; Raudenbush \& Bryk, 2002). The IRT scale scores in the ECLS-K database represent estimates of the number of items students would have answered correctly if they had answered all questions, and the scores at different grades are directly comparable without going through an equating process (Hox, 2002; Tourangeau et al., 2006).

The examination of Figure 1 revealed the performance of ELL students was significantly low in kindergarten and then fell significantly further behind in third and fifth grades when compared to the performance of their English-only counterparts. The initial gap between English-speaking and ELL groups in kindergarten was 8.208 (English-speaking $=34.811$ vs. $E L L=26.603$ ), and the gap in the fifth grade was 11.972 (English-speaking $=115.577$ vs. $E L L=103.605)$.

\section{Cross-Sectional Analysis}

The results of cross-sectional analyses showed the effects of computer uses on math performance of students at four grades, when the effects of SES, age, language status and gender were controlled for. Home computer access was positively associated with the math achievement of English-speaking students from kindergarten to fifth grade. In particular, Caucasian English-speaking students who had home computers demonstrated significantly higher math performance than did those who did not have home computers in all four grades (kindergarten: $\beta=1.437, p<.01$; first grade: $\beta=1.702, p<.01$; third grade: $\beta=3.775$, $p<.01$; and fifth grade: $\beta=8.439, p<.01$ ). For English-speaking students in the other racial groups, the significant effects of home computers were found in the early grades: kindergarten for black students $(\beta=1.778, p<.01)$; kindergarten $(\beta=2.256, p<.01)$ and first grade $(\beta=1.764, p<.05)$ for Hispanic students; and kindergarten for Asian students $(\beta=2.084, \pi<.05)$.

Home computers for ELL students displayed significant effects in both Caucasian and Hispanic groups. The effects of home computers were negative for Caucasian ELL students in all four grades, with particularly significant effects in the third $(\beta=-25.189, p<.01)$ and fifth grades $(\beta=-24.444, p<.05)$. In other words, when Caucasian ELL students had computers at home, they tended to show lower math achievement scores compared to Caucasian English-speaking students without home computers. Similarly, when Hispanic ELL students in 


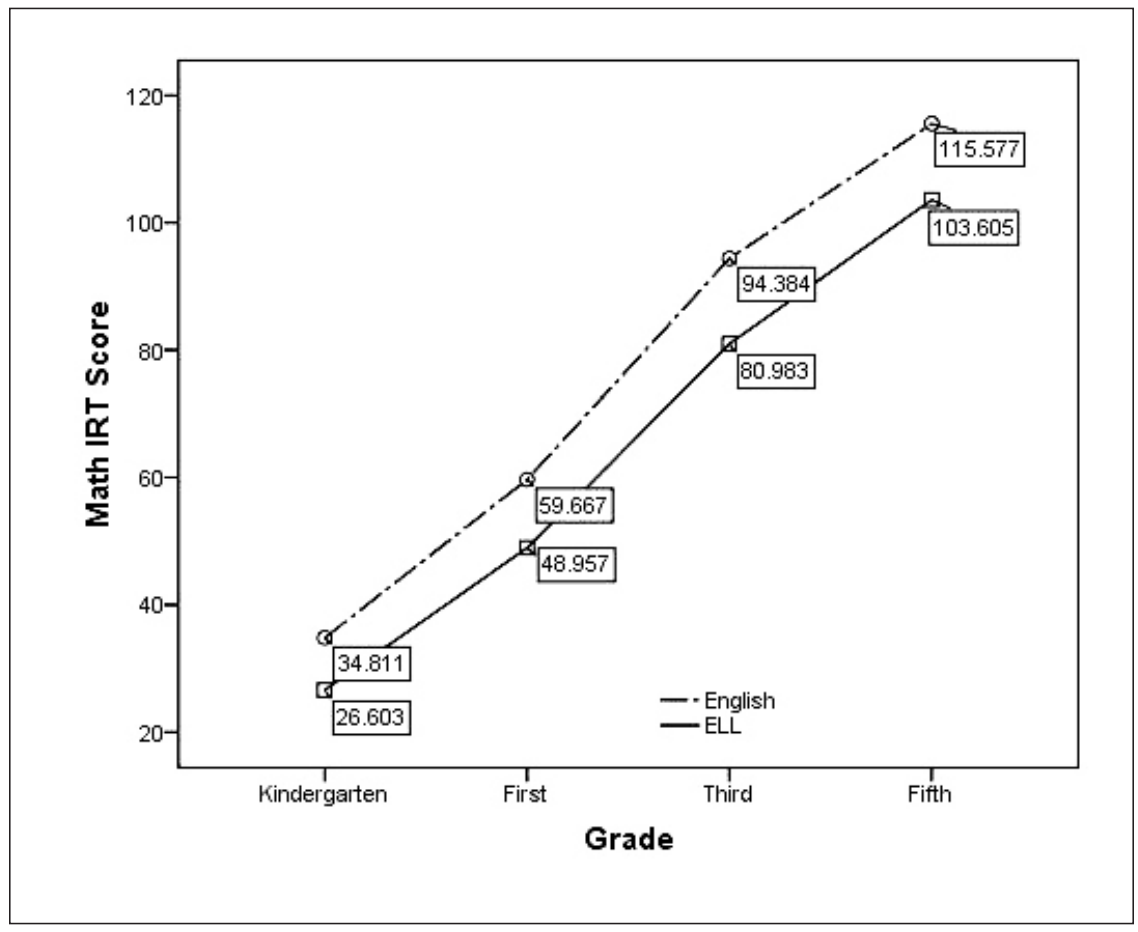

Figure 1. Math achievement pattern of students from two linguistic groups.

kindergarten had home computers, they demonstrated significantly lower math achievement scores $(\beta=-2.821, p<.01)$ as compared to Hispanic Englishspeaking students without home computers.

The study noted consistent benefits from computer use for various purposes for English-speaking students from all four racial groups (see details in Table 1), indicating that when English-speaking students used computers for various purposes, they tended to show high performance in math. However, the effects of computer use for various purposes for ELL students were significant only for black students in the early grades (kindergarten: $\beta=3.143, p<.01$; first grade: $\beta=3.271, p<.01)$. That is, when black ELL students in kindergarten and the first grade used computers for various purposes, they tended to display higher math performance when compared to black English-speaking students who did not use computers for various purposes.

Different from the overall benefit of the above two computer variables for English-speaking students, the frequent use of computers in math classes by 
Table 1. Results of Cross-Sectional Analyses

\begin{tabular}{|c|c|c|c|c|c|c|c|c|}
\hline & \multicolumn{8}{|c|}{ Caucasian } \\
\hline & \multicolumn{2}{|c|}{$\begin{array}{c}\text { Kindergarten } \\
\beta(S E)\end{array}$} & \multicolumn{2}{|c|}{$\begin{array}{c}1 \mathrm{st} \\
\beta(S E)\end{array}$} & \multicolumn{2}{|c|}{$\begin{array}{c}\text { 3rd } \\
\beta(S E)\end{array}$} & \multicolumn{2}{|c|}{$\begin{array}{c}\text { 5th } \\
\beta(S E)\end{array}$} \\
\hline ELL & 4.265 & $(3.43)$ & 2.348 & $(2.70)$ & $17.104^{\star *}$ & * $(4.99)$ & 2.336 & (10.89) \\
\hline Age & $0.339 * *$ & ${ }^{*}(0.02)$ & $0.157^{* *}$ & ${ }^{*}(0.03)$ & $0.173^{* *}$ & $*(0.06)$ & 0.124 & $(0.08)$ \\
\hline SES & $2.979 * *$ & ${ }^{*}(0.08)$ & $2.533^{* *}$ & ${ }^{*}(0.18)$ & $5.808^{* *}$ & * $(0.37)$ & $6.795^{\star \star}$ & * $\quad(0.51)$ \\
\hline Gender & -0.329 & $(0.18)$ & $0.852^{\star *}$ & * $(0.23)$ & $4.726^{* \star}$ & * $(0.49)$ & 3.291 ** & ${ }^{*} \quad(0.70)$ \\
\hline \multicolumn{9}{|l|}{ Step 2} \\
\hline HomeCom & $1.437^{\star *}$ & ${ }^{*}(0.10)$ & $1.702^{\star *}$ & * $(0.32)$ & $3.775^{\star *}$ & * $(0.83)$ & $8.439 * *$ & * (1.38) \\
\hline ComPurpose & $2.451 * *$ & ${ }^{*}(0.14)$ & $1.944^{\star *}$ & ${ }^{*}(0.12)$ & $4.875^{\star \star}$ & * $(0.25)$ & $6.900 * *$ & * $(0.34)$ \\
\hline MathCom & $-0.421^{*}$ & $(0.17)$ & -0.086 & $(0.18)$ & -0.362 & $(0.30)$ & $-1.332^{\star *}$ & * $(0.39)$ \\
\hline \multicolumn{9}{|l|}{ Step 3} \\
\hline ELLHomCom & -2.106 & $(1.27)$ & -5.367 & $(2.87)$ & $-25.189^{* *}$ & * $(5.49)$ & $-24.444^{\star}$ & (11.85) \\
\hline ELComPurpose & -1.233 & $(1.42)$ & -0.198 & $(1.23)$ & 4.556 & (2.68) & -4.834 & (4.37) \\
\hline ELLMathCom & -0.803 & $(1.05)$ & 2.352 & $(2.31)$ & 0.026 & $(1.55)$ & $-10.145^{\star}$ & (4.40) \\
\hline \multirow[t]{2}{*}{ Total $R^{2}$} & $0.253^{* *}$ & & $0.209^{* *}$ & & $0.287^{* x}$ & & $0.302^{\star *}$ & \\
\hline & \multicolumn{8}{|c|}{ Hispanic } \\
\hline \multicolumn{9}{|l|}{ Step 1} \\
\hline ELL & -1.418 & $(0.87)$ & $-3.635^{* *}$ & * $(1.35)$ & -0.625 & $(2.61)$ & -11.590 ** & ** $(2.92)$ \\
\hline Age & $0.366^{* *}$ & ${ }^{*}(0.04)$ & $0.212^{* *}$ & ${ }^{*}(0.06)$ & $0.609 * *$ & * $(0.18)$ & $0.527^{* \star}$ & ** $(0.16)$ \\
\hline SES & 3.034 ** & ${ }^{*}(0.19)$ & $1.856^{\star}$ & $(0.76)$ & $5.422^{* \star}$ & * $(1.04)$ & $7.243^{* *}$ & ** $(1.14)$ \\
\hline Gender & $0.469 *$ & $(0.19)$ & $0.958^{*}$ & $(0.46)$ & 3.031 & (1.62) & $3.289 *$ & * (1.37) \\
\hline \multicolumn{9}{|l|}{ Step 2} \\
\hline HomeCom & $2.256^{* *}$ & ${ }^{*}(0.25)$ & $1.764^{\star}$ & $(0.77)$ & 2.630 & $(1.90)$ & 0.483 & (1.94) \\
\hline ComPurpose & $1.797^{* *}$ & ${ }^{*}(0.15)$ & $1.978^{* *}$ & ${ }^{*}(0.22)$ & $4.491^{* *}$ & * $(0.76)$ & $7.403^{* *}$ & ** $(0.74)$ \\
\hline MathCom & -0.339 ** & ${ }^{*}(0.12)$ & -0.582 & $(0.45)$ & 1.296 & $(0.77)$ & $-1.680^{*}$ & ${ }^{*} \quad(0.77)$ \\
\hline \multicolumn{9}{|l|}{ Step 3} \\
\hline ELLHomCom & -2.821 ** & ${ }^{*}(0.51)$ & -0.924 & $(1.11)$ & -2.785 & (3.54) & 2.859 & (3.62) \\
\hline ELComPurpose & 0.005 & $(0.14)$ & 0.349 & $(0.46)$ & 0.917 & (1.19) & -0.958 & (1.76) \\
\hline ELLMathCom & 0.251 & $(0.33)$ & -0.103 & $(0.63)$ & $-3.585^{\star}$ & $(1.52)$ & $5.347^{* *}$ & ** (2.01) \\
\hline Total $R^{2}$ & $0.296^{\star *}$ & & $0.234^{* *}$ & & $0.247^{* *}$ & & $0.346^{\star *}$ & \\
\hline
\end{tabular}

${ }^{\star} p<0.05,{ }^{* *} p<0.01$. 
COMPUTER FOR ELL MATH ～/ 297

\begin{tabular}{|c|c|c|c|c|}
\hline \multicolumn{5}{|c|}{ Black } \\
\hline $\begin{array}{c}\text { Kindergarten } \\
\beta(S E)\end{array}$ & $\begin{array}{c}\text { 1st } \\
\beta(S E)\end{array}$ & & $\begin{array}{c}3 r d \\
\beta(S E)\end{array}$ & $\begin{array}{c}\text { 5th } \\
\beta(S E)\end{array}$ \\
\hline$-11.582^{\star *}(3.47)$ & -1.803 & $(5.31)$ & $-1.601 \quad(10.17)$ & -19.767 \\
\hline $0.334 * *(0.03)$ & $0.131^{*}$ & $(0.07)$ & $0.574^{* *}(0.22)$ & $-.266 \quad(0.19$ \\
\hline $1.737^{\star \star}(0.20)$ & $1.878^{* *}$ & $(0.37)$ & $7.018^{\star \star}(1.09)$ & $11.855^{\star *}(1.62$ \\
\hline $0.56^{*} \quad(0.27)$ & -0.013 & $(0.54)$ & $3.651^{* *}(1.36)$ & $2.913 \quad$ (1.92 \\
\hline $1.778^{* *}(0.31)$ & 1.053 & $(0.69)$ & $1.835 \quad(1.31)$ & 1.493 \\
\hline $2.441 * *(0.16)$ & $2.302^{* *}$ & $(0.24)$ & $4.794^{\star *}(0.45)$ & $5.644^{* *}(0.84)$ \\
\hline$-0.417^{*}(0.18)$ & -0.304 & $(0.24)$ & $-0.293 \quad(0.89)$ & $-0.800 \quad(0.96$ \\
\hline$-1.923 \quad(2.05)$ & -1.117 & $(3.45)$ & $4.314 \quad(8.00)$ & 33.186 \\
\hline $3.143^{* *}(1.09)$ & $3.271^{* *}$ & (1.04) & $-2.656 \quad(3.33)$ & 8.313 \\
\hline $0.121 \quad(1.05)$ & $-4.312^{\star}$ & $(1.78)$ & $-6.725 \quad(4.434)$ & $28.163^{*}$ \\
\hline $0.255^{\star *}$ & \multicolumn{2}{|l|}{$0.195^{\star *}$} & $0.302^{* *}$ & $0.295^{\star *}$ \\
\hline \multicolumn{5}{|c|}{ Asian } \\
\hline $3.886^{*}(1.84)$ & 1.462 & (3.25) & $-9.002^{*}(4.12)$ & $-9.732 \quad(6.87$ \\
\hline $0.414^{* \star}(0.10)$ & $0.398^{* *}$ & $(0.15)$ & $0.634^{* *}(0.21)$ & $0.777^{\star *}(0.29$ \\
\hline $3.269 * *(0.40)$ & $2.845^{\star \star}$ & $(0.72)$ & $4.996^{\star *}(1.24)$ & $9.528 * *(1.28)$ \\
\hline$-0.480 \quad(0.81)$ & $1.921 *$ & $(0.85)$ & $2.404 \quad(1.72)$ & $10.760 * *(2.22$ \\
\hline $2.084^{*}(0.76)$ & 0.120 & $(1.23)$ & $-1.751 \quad(2.23)$ & 2.205 \\
\hline $2.655^{\star \star}(0.42)$ & $2.711 * \star$ & $(0.52)$ & $6.354^{* \star}(0.98)$ & $6.824^{* *}(1.25$ \\
\hline$-0.023 \quad(0.45)$ & -0.916 & $(1.11)$ & $0.863 \quad(1.22)$ & 0.264 \\
\hline$-1.086 \quad(0.72)$ & -1.655 & $(2.12)$ & $6.883 \quad(4.85)$ & -1.823 \\
\hline$-0.766 \quad(0.50)$ & -0.466 & $(0.94)$ & $1.363 \quad(1.63)$ & 3.075 \\
\hline$-0.705 \quad(0.73)$ & 0.067 & $(1.36)$ & $-2.557 \quad(2.16)$ & $9.014 *$ \\
\hline $0.290 * *$ & $0.313^{* *}$ & & $0.404^{\star *}$ & $0.590 * *$ \\
\hline
\end{tabular}


English-speaking students revealed negative effects. The majority of Englishspeaking students were likely to display lower math achievement scores when they frequently used computers for math. In particular, the effects were significantly negative for Caucasian students (kindergarten: $\beta=-0.421, p<.05$; fifth grade: $\beta=-1.332, p<.01$ ), Black students (kindergarten: $\beta=-0.417, p<.05$ ) and Hispanic students (kindergarten: $\beta=-0.339, p<.01$; fifth grade: $\beta=-1.680$, $p<.01)$.

The effects of the frequent use of computers for math on ELL students did not show a consistent pattern. A significantly negative effect was noted for Caucasian ELL students in fifth grade $(\beta=-10.145, p<.05)$ indicating that when ELL Caucasian fifth graders used computers for math frequently, they tended to show lower math performances compared with their English-speaking counterparts. However, other ELL students in the fifth grade who frequently used computers for math showed a tendency to perform better in math (Black: $\beta=28.163, p<.05$; Hispanic: $\beta=5.347, p<.01$; Asian: $\beta=9.014, p<.05$ ) when compared to their English-speaking counterparts.

\section{Longitudinal Analysis}

The longitudinal analysis results revealed the longitudinal effects of computer variables on the mathematical achievement of students after controlling for the effects of the other covariates (language status, SES, gender, and age). Computer access at home had a positive effect on the math performance of English-speaking students. The effect was especially significant for Caucasian students $\left(\beta_{30}=\right.$ $3.545, p<.01)$. When Caucasian English-speaking students had computer access at home, they displayed a higher growth rate in math from kindergarten to fifth grade than Caucasian English-speaking students without a computer at home. Although positive longitudinal effects were noted for ELL students, the effects were not significant.

The longitudinal effect of computer use for various purposes was significant for students from both Caucasian and Asian English-speaking groups. Its longitudinal effect for Caucasian English-speaking students was $\beta_{40}=0.488(p<.05)$ and for Asian English-speaking students was $\beta_{40}=1.925(p<.01)$. When Caucasian and Asian English-speaking students frequently used the computer for various purposes, their math performance increased significantly over the years. It is important to note that the longitudinal effect of computer use for various purposes was significant for Hispanic ELL students $\left(\beta_{40}=1.297, p<.05\right)$. In other words, when Hispanic ELL students used computers frequently for various purposes, they displayed a higher growth rate of math performance as compared to Hispanic English-speaking students.

In contrast, the frequent use of computers to learn math had a differential longitudinal effect on the math achievement of English-speaking and ELL students. When Hispanic and Asian English-speaking students frequently used 
computers for math, their math performance decreased over the time (Hispanic: $\beta_{50}=-1.191, p<.05$; Asian: $\left.\beta_{50}=-1.771, p<.01\right)$. On the other hand, when Hispanic and Asian ELL students used a computer frequently in math classes, their growth rates in math performance were significantly higher than those of their English-speaking peers (Hispanic: $\beta_{51}=1.902, p<.01$; Asian: $\beta_{51}=$ $2.789, p<.05$ ) (see Table 2).

\section{DISCUSSION}

This study is motivated by the same concern that many American educators share over the low mathematical performance of U.S. students, especially ELL students (Abedi, 2002; Albus et al., 2002; Clarkson, 2008; Reardon \& Galindo, 2007). The study used a U.S. representative database on elementary school students and confirmed the existence of similar findings in previous studies done by many researchers with regard to the performance levels of ELL students. The study found a significant performance gap between native English-speaking and ELL students throughout the elementary school years; the initial significant gap in the kindergarten year became wider in the higher grades.

As a way to improve the mathematical performance of U.S. students, the study explored computers as an important educational resource. By adopting proper weights and treating design effects, the study results achieved a high generalizability and provided empirical results regarding computer use for both native English-speaking and ELL students. Thus, this study aims at a practical and theoretical contribution to the body of knowledge on the academic success of ELL students, upon which little research has been done (Clarkson, 2008).

To explore the effects of computer use, the study used three computer variables (home computer access, computer use for various educational purposes, and computer use to learn math) after controlling for the effects of SES, gender, language status, and age. By splitting the database into four separate racial groups (Caucasian, Black, Hispanic, and Asian), the study performed both cross-sectional and longitudinal analyses.

Home computer access has an overall positive effect for English-speaking students. In particular, home computer access had significantly positive effects for Caucasian English-speaking students for both direct and longitudinal effects. The study results mirrored previous findings on the positive effect of home computer access and use on mathematical achievement of U.S. students overall (Du et al., 2004; Papanastasiou \& Ferdig, 2006).

However, access to a home computer has a negative, direct effect for ELL students, especially Hispanic kindergarteners. Fuchs and Wößmann's study (2005) suggested important implications for Hispanic ELL students in terms of computer use at home. According to their study results, mere access to a computer at home had a negative effect, but computer use at home that was guided for educational purposes had a positive effect on students' math achievement. Based 
300 / KIM AND CHANG

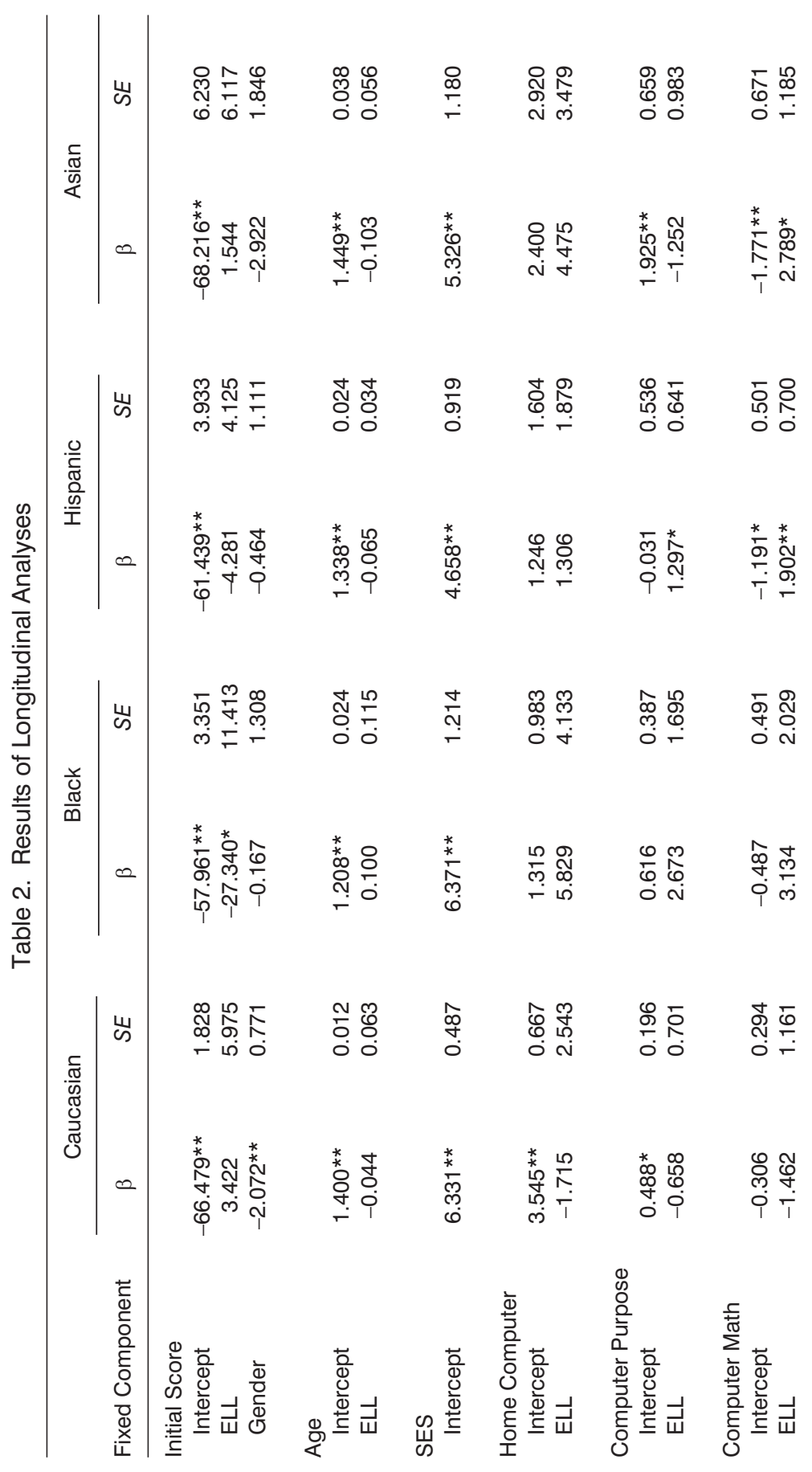


COMPUTER FOR ELL MATH ～/ 301

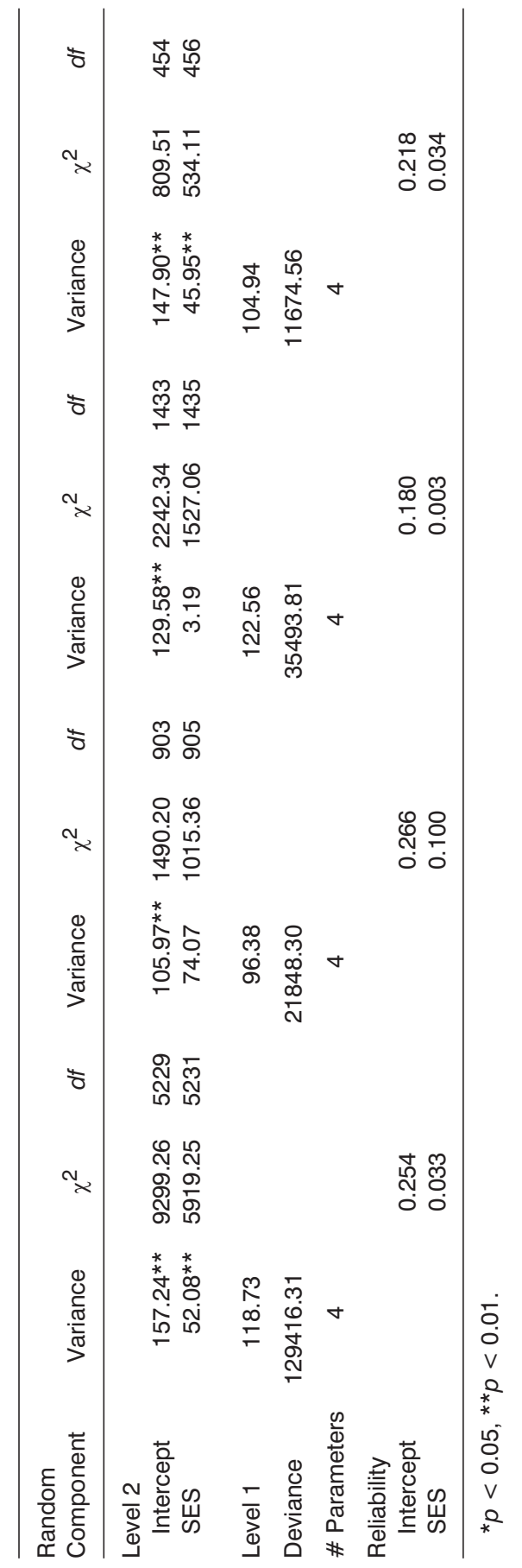


on the findings of the study, we also suggest that parents monitor Hispanic ELL kindergarteners at home, providing guidelines for the use of home computers and helping students to use computers for educational purposes.

Through cross-sectional analyses, computer use for various purposes indicated significantly positive effects for English-speaking students from all four racial groups. The longitudinal analysis showed significantly positive effects for Caucasian and Asian English-speaking students. Among ELL students, computer use for various purposes exerted a significantly positive, direct effect on black ELL students and a positive longitudinal effect on Hispanic ELL students. The study results are aligned with the previous studies indicating the positive effects of computer use for various purposes (Fuchs \& Wößmann, 2005; Papanastasiou \& Ferdig, 2006).

It is important to note that computer use for math was associated with a reduced gap in math performance between native English-speaking and ELL students. Cross-sectional analyses revealed that computer use for math had overall negative effects for English-speaking students. On the contrary, Black, Hispanic, and Asian ELL fifth graders showed high math performances when they frequently used computers for math. Just as we observed in the cross-sectional analyses, computer use for math resulted in a reduced gap in math for Hispanic and Asian students in the longitudinal analysis. This finding contradicts the previous studies that showed a positive effect on the mathematical achievement of general population students without considering the linguistic and ethnic status of students (Lei \& Zhao, 2007; Mendicino et al., 2009). Therefore, the gap-reducing effect of computer use for math is a new finding of this study.

Summarizing the study's results, we recommend that educators carefully select ways to utilize computers for students with diverse backgrounds. We found positive effects from having a home computer and from computer use for various purposes for English-speaking groups. Therefore, we suggest that teachers need to encourage English-speaking students to use computers at home and for various purposes. However, teachers need to pay careful attention when utilizing computers to teach math to Hispanic and Asian English-speaking students during the class, as the study's results indicated negative effects of computer use for math on Hispanic and Asian English-speaking students. Also, teachers need to encourage Hispanic and Asian English-speaking students in the higher grades to use computers for more various purposes as previous studies have supported (Fuchs \& Wößmann, 2005; Papanastasiou \& Ferdig, 2006).

In particular, we noted an important finding for Hispanic ELL students: computer use for educational purposes played a more influential role in their math performance. While general access to home computers had a negative effect for Hispanic ELL students, computer use for math class and for various educational purposes had a positive effect. Using this finding, we exhort teachers and parents to guide Hispanic ELL students to use computers for educational purposes at home and in school. 
Another finding of computer use relating to racial and linguistic groups is the significantly positive effect of computer use for math for Asian ELL students. Against our expectation that both English-speaking and ELL students would gain benefits from computer use for various purposes and for math, only the effect of computer use for math turned out to be significant for the Asian ELL group. We attribute the significant effect of computer use for math to specific characteristics of the Asian ELL group, which has been much exposed to computers, yet has a limited English proficiency for using computers freely for various educational purposes. In this interpretation, we shared the notion of scholars who demonstrated that many ELL students indicated difficulties following instructions for computer use and participating in educational activities using computers (Prinsen et al., 2007).

ELL students can benefit from using computers for math as they can get some additional verbal or non-verbal support from teachers when using computers in math classes (Segers et al., 2004). However, a caution should accompany the observations about computer use for various purposes. Using computers for various purposes oftentimes require higher levels of English skills because students have to understand computer instructions and software. To guide ELL students to use computers efficiently for various purposes, we suggest that computer programs should include instrumental features to aid their limited English language skills. Good examples can be text-to-speech read-aloud functionality, bilingual features, and content delivery options via texts, pictures, or movies (Anger et al., 2004; Proctor et al., 2007).

The study found important empirical results by applying statistical methods with proper treatments to a large scale database. However, this study is limited, as it was based on a survey questionnaire, which makes causal inferences only tentative. Therefore, this study recommends further research to investigate the direct effects of computers with specific features for ELL students where randomized, controlled experiments are feasible. Despite the limitation, the study satisfied a need to understand better how students' math achievement is related to their computer access at home, computer uses for various purposes, and computer use for math. This is especially important for students from racial and linguistic minority backgrounds, for whom there is a dearth of research.

\section{REFERENCES}

Abedi, J. (2002). Standardized achievement tests and English language learners: Psychometrics issues. Educational Assessment, 8(3), 231-257.

Albus, D., Thurlow, M., \& Liu, K. (2002). Participation and performance of English language learners reported in public state documents and web sites, 1999-2000. LEP projects report. Minneapolis, MN: National Center on Educational Outcomes. 
American Institutes for Research. (2006). AM Statistical Software Beta (Version 0.06.03) [Computer software]. Washington, DC: Author.

Anger, W. K., Tamulinas, A., Uribe, A., \& Ayala, C. (2004). Computer-based training for immigrant Latinos with limited formal education. Hispanic Journal of Behavioral Sciences, 26(3), 373-389.

Clarkson, L. M. C. (2008). Demographic data and immigrant student achievement. Theory Into Practice, 47(1), 20-26.

Du, J., Havard, B., Yu, C., \& Adams, J. (2004). The impact of technology use on lowincome and minority students' academic achievement: Educational Longitudinal Study of 2002. Journal of Educational Research \& Policy Studies, 4(2), 21-38.

Fuchs, T., \& Wößmann, L. (2005). Computers and student learning: Bivariate and multivariate evidence on the availability and use of computers at home and at school. Retrieved from http://www.cesifo.de/pls/guest/download/Ifo\%20Working\%20Papers $\% 20$ (seit\%202005)/IfoWorkingPaper-8.pdf

Gerbic, P. (2006). Chinese learners and online discussions: New opportunities for multicultural classrooms. Research and Practice in Technology Enhanced Learning, 1(3), 221-237.

Hox, J. J. (2002). Multilevel analysis: Techniques and applications. Mahwah, NJ: Lawrence Erlbaum Associates.

Kilpatrick, J., Swafford, J., \& Findell, B. (Eds.). (2001). Adding it up: Helping children learn mathematics. Washington, DC: National Academy Press.

Lee, J., Grigg, W., \& Dion, G. (2007). The nation's report card: Mathematics 2007 (NCES 2007-494). National Center for Education Statistics, Institute of Education Sciences, U.S. Department of Education, Washington, DC.

Lei, J., \& Zhao, Y. (2007). Technology uses and student achievement: A longitudinal study. Computers \& Education, 49(2), 284-296.

Mendicino, M., Razzaq, L., \& Heffernan, N. T. (2009). A comparison of traditional homework to computer-supported homework. Journal of Research on Technology in Education, 41(3), 331-359.

Meskill, C. (2005). Triadic scaffolds: Tools for teaching English language learners with computers. Language Learning \& Technology, 9(1), 46-59.

National Clearinghouse for English Language Acquisition \& Language Instruction Educational Programs (NCELA). (2009). The growing numbers of limited English proficient students. Retrieved August 19, 2009, from http://www.ncela.gwu.edu/files/uploads/ 4/GrowingLEP_0506.pdf

Papanastasiou, E. C., \& Ferdig, R. E. (2006). Computer use and mathematical literacy: An analysis of existing and potential relationships. Journal of Computers in Mathematics and Science Teaching, 25(4), 361-371.

Parmar, P., Harkness, S., \& Super, C. M. (2008). Teacher or playmate? Asian immigrant and Euro-American parents' participation in their young children's daily activities. Social Behavior and Personality, 36(2), 163-176.

Pearson, G. (2009). Ask NCELA No.1: How many school-aged English-language learners (ELLs) are there in the U.S.? Washington, DC: National Clearing House for English Language Acquisition \& Language Instruction Educational Programs.

Prinsen, F., Volman, M. L. L., \& Terwel, J. (2007). The influence of learner characteristics on degree and type of participation in a CSCL environment. British Journal of Educational Technology, 38(6), 1037-1055. 
Proctor, C. P., Dalton, B., \& Grisham, D. L. (2007). Scaffolding English language learners and struggling readers in a universal literacy environment with embedded strategy instruction and vocabulary support. Journal of Literacy Research, 39(1), 71-93.

Provasnik, S., Gonzales, P., \& Miller, D. (2009). U.S. performance across international assessments of student achievement: Special supplement to the condition of education 2009 (NCES 2009-083). National Center for Education Statistics, Institute of Education Sciences, U.S. Department of Education. Washington, DC.

Raudenbush, S. W., \& Bryk, A. S. (2002). Hierarchical linear models: Applications and data analysis methods (2nd ed.). Thousand Oaks, CA: Sage.

Reardon, S. F., \& Galindo, C. (2007). Patterns of Hispanic students' math skill proficiency in the early elementary grades. Journal of Latinos and Education, 6(3), 229-251.

Segers, E., Takke, L., \& Verhoeven, L. (2004). Teacher-mediated versus computermediated storybook reading to children in native and multicultural kindergarten classrooms. School Effectiveness and School Improvement: An International Journal of Research, Policy and Practice, 15(2), 215-226.

Tourangeau, K., Nord, C., Le, T., Pollack, J. M., Atkins-Burnett, S., \& Hausken, E. G. (2006). Early childhood longitudinal study, kindergarten class of 1998-99 (ECLS-K): Combined user's manual for the ECLS-K fifth-grade data files and electronic codebooks. Washington, DC: National Center for Education Statistics and U.S. Department of Education Institute of Education Sciences.

Direct reprint requests to:

Dr. Sunha Kim

Virginia Tech

304 E. Eggleston Hall

Blacksburg, VA 24061

e-mail: sunkim@vt.edu 
Copyright of Journal of Educational Computing Research is the property of Baywood Publishing Company, Inc. and its content may not be copied or emailed to multiple sites or posted to a listserv without the copyright holder's express written permission. However, users may print, download, or email articles for individual use. 